\title{
Colecionadores, coleções particulares e o mercado brasileiro de arte contemporânea ${ }^{1}$
}

DAYANA ZDEBSKY DE CORDOVA

Dayana Zdebsky de Cordova é antropóloga, mestre pela Universidade Federal do Paraná, doutoranda pela Universidade Federal de São Carlos. Pesquisa arte contemporânea desde a graduação, passando por ações de/na rua; editais e a formação institucional do artista e, agora no doutorado, mercado de arte contemporânea a partir do colecionismo. Fora da academia, como antropóloga, dedicou-se a pesquisas na área do patrimônio imaterial e material urbano. É coautora dos livros Alfaiatarias em Curitiba (2009), Pelos trilhos: paisagens ferroviárias de Curitiba (2010), As muitas vistas de uma rua: histórias e políticas de uma paisagem (2014). Como produtora, atuou em diferentes projetos relativos às artes contemporâneas cênicas e visuais. É coautora do livro Conversas sobre arte (2015), que traz entrevistas com diferentes atores das artes visuais residentes em Curitiba.

\footnotetext{
${ }^{1} \mathrm{O}$ presente artigo baseia-se em uma pesquisa de campo realizada entre os anos de 2012 e 2016, referente ao projeto de pesquisa "Especular Arte" que desenvolvo em meu doutorado no Programa de Pós-Graduação em Antropologia Social da Universidade Federal de São Carlos (PPGAS/UFSCar), em grande parte realizado graças à uma bolsa concedida pelo Conselho Nacional de Pesquisa Científica (CNPq). Considera, ainda, experiências de pesquisas anteriores, relativas à dissertação "As artes visuais e seus fluxos..." (CORDOVA, 2010), à monografia "Flânerie..." (CORDOVA, 2006) e ao projeto do livro "Conversas sobre arte" (BURIGO, CORDOVA, 2015). Ele é a versão escrita da palestra proferida dia 07/06/2017 no Instituto Ling, em Porto Alegre/RS, dentro do projeto "Cultura em Miniciclos", com o tema "Colecionismo e arte". A palestra foi realizada a convite de Lucas Ribeiro, ao qual sou grata pela provocação para traçar as reflexões aqui apresentadas. Agradeço também a Nei Vargas da Rosa pela oportunidade de publicar este artigo e pela leitura cuidadosa do mesmo.
} 


\section{RESUMO}

O colecionador, no contexto das artes visuais contemporâneas, é uma figura poderosa e, para muitos, misteriosa. Para além do que o estereótipo do rico excêntrico (ou, mais recentemente, no Brasil, do corrupto recebedor de propina ou que lava dinheiro), os colecionadores são diferentes entre si, desde suas capacidades financeiras para aquisição de obras às suas relações com a arte, passando por diferentes motivações para adquirir e colecionar obras. O presente artigo é uma reflexão introdutória sobre o colecionismo e coleções feita a partir de uma pesquisa etnográfica sobre o mercado brasileiro de arte contemporânea, realizada descontinuamente entre os anos de 2012 e 2016.

\section{PALAVRAS-CAVE}

Colecionador, coleção, obra de arte, artista, mercado.

\section{ABSTRACT}

The collector, within the context of the contemporary visual arts, is a powerful and, for many, mysterious figure. Beyond the stereotype of the eccentric rich (or, more recently, in Brazil, the corrupt recipient of money bribes or money launderer buying art), collectors are different amongst themselves, both in their financial capacity to buy works as well as their relationship with art itself, in addition to their different motivations for acquiring and collecting works of art. This article is an introductory reflection on collecting and collections stemming from an ethnographic research on the Brazilian contemporary art market performed discontinuously between the years of 2012 and 2016

\section{KEYWORDS}

Art collector, art collection, work of art, artist, art market.

Em se tratando de mercado de arte, particularmente do mercado de arte contemporânea, a figura do colecionador é poderosa e, para muitos leigos, misteriosa. Dentro do sistema da arte ${ }^{2}$, mais especificamente do sistema das artes visuais contemporâneas ${ }^{3}$, o mercado de arte é território de uma expertise bastante específica. Dúvidas, sombras e, principalmente, desconfianças daqueles que não têm intimidade com esse mercado, pairam sobre ele. No contexto brasileiro, isso aparece

\footnotetext{
${ }^{2} \mathrm{~A}$ imagem de um sistema da arte aqui acionada e que ecoa por este volume da "ouvirOUver" é, hoje, utilizada por diferentes atores das artes visuais para referir-se ao "conjunto de indivíduos e instituições responsáveis pela produção, difusão e consumo de objetos e eventos por eles mesmo rotulados como artísticos e responsáveis também pela definição dos padrões e limites da arte para toda uma sociedade, ao longo de um período históriCO" (BULHÕES, 2014, p.15 e 16). Muitos de meus interlocutores afirmam que a autora citada, Maria Amelia BuIhões, foi a primeira a acionar tal conceito no Brasil em sua tese no início da década de 1990, em diálogo com os escritos de Pierre Bourdieu sobre o campo artístico e de Howard Becker sobre o mundo da arte.

${ }^{3}$ Essa especificação é relativa à compreensão de que o sistema das artes visuais não corresponde a totalidade da arte, assim como reconhece a pluralidade existente dentro das artes visuais contemporâneas.
} 
particularmente em sistemas locais de arte 4 que têm, nas palavras de seus especialistas, um "mercado de arte pouco consolidado"5. Se o colecionador - utilizo aqui o termo no masculino não por mera convenção de nossa língua, mas porque, em sua grande maioria, dentro do escopo de minha pesquisa, tratam-se de homens (brancos) - já é uma figura desejada e ao mesmo tempo distante, inalcançável, para grande parte dos atores da arte contemporânea em locais onde o mercado de arte se faz mais presente (no caso brasileiro, Rio de Janeiro e, principalmente, São Paulo), ele o é ainda mais nas cidades periféricas ao mercado - mesmo que nelas habite, em geral não é nelas, ou com vendedores nelas sediados, que faz suas aquisições.

O poder do colecionador de arte para o mercado reside, em parte, na sua presença como cliente preferencial das galerias. Trata-se de alguém que, ideal e potencialmente, realiza compras frequentemente e, de acordo com a expressividade/reconhecimento de sua coleção, é capaz de valorizar artística e financeiramente aquilo que adquire. Seu investimento enquanto um comprador especializado pode funcionar como indício e lastro da qualidade de obras e artistas. São clientes valiosos dentro do mercado de arte, protegidos por seus provisores, com quem podem manter relações de fidelidade, comprando obras de arte apenas com eles. Galerias de pequeno porte têm poucos colecionadores em sua cartela de clientes e, como as demais, não os expõem a qualquer um (como, por exemplo, uma pesquisadora antropóloga não atuante no mercado), seja para não incomodá-los com curiosos ou pessoas não galeristas desejosas de vender obras de arte, seja para não correr o risco de migrarem para outras galerias. A discrição e um certo segredo fazem parte das estratégias de negócio da arte contemporânea, assim como a exposição e a publicização de certas situações ou informações (como acontece, por exemplo, quando os galeristas acionam o nome de certos colecionadores e suas respectivas aquisições para fomentar novas vendas).

Este artigo concentra-se nos colecionadores particulares de arte contemporânea, pessoas físicas - incluindo aquelas que porventura criaram pessoas jurídicas para abrigar suas coleções, mas que partiram de coleções particulares ${ }^{6}$. Não me refiro aqui a outras tantas possibilidades de colecionismo de arte contemporânea, como as coleções afetivas de artistas, construídas com obras de arte ganhas

\footnotetext{
${ }^{4}$ Aciono aqui a imagem de sistemas locais de arte pautada em minha pesquisa de campo, cujos atores em inúmeros momentos distinguiram retórica e conceitualmente uma arte paranaense, uma arte brasileira ou latino americana. Mais do que uma questão de escala, esses locais parecem possuir características específicas em sua produção artística. Penso, ainda, na afirmação do antropólogo Clifford Geertz (1997) que, na década de 1980, colocava que todo sistema de arte é necessariamente local. Mas há locais tidos como mais totais ou globais que os demais, enquanto outros locais são mais locais. É o caso, por exemplo, quando os atores pesquisados se referem à arte produzida em Nova York como arte contemporânea, à arte produzida na cidade de São Paulo como uma arte contemporânea brasileira e a arte produzida em Curitiba como arte paranaense (ver mais em CORDOVA, 2016 e FIALHO, 2011, dentre outros).

5 Por mercado de arte pouco consolidado compreende-se aquele mercado que não é significativo, equilibrado, frente ao sistema das artes visuais - onde, por exemplo, a atuação dos museus, as leis de incentivo à cultura e seus editais mobilizam grande parte da economia relacionada às artes visuais (para mais discussões sobre leis de incentivo ver CORDOVA, 2010 e ROSA, 2014). O mercado de arte é centrado em cidades consideradas grandes centros econômicos, muito embora esses centros do mercado possam se deslocar contextualmente com grandes eventos, como as feiras de arte (mais sobre feiras de arte, ver FETTER, 2014 e 2016; mais sobre mercado de arte em grandes centros brasileiros ver STOCCO, 2016; BERTOLOSSI, 2015 e sobre a discussão de localidades $\mathrm{X}$ centros em uma escala internacional a partir da experiência brasileira, ver FIALHO, 2011, dentre outros).

${ }^{6} \mathrm{E}$ trata-se, mais do que um artigo sobre coleções e colecionismo, de um artigo que pensa as narrativas sobre coleções e colecionismo que circulam no mercado brasileiro mainstream de arte contemporânea.
} 
ou trocadas entre amigos (e que explicitam suas redes de relações no mundo da arte); ou coleções de coisas que os artistas fazem para compor obras de arte, como as peças que Cildo Meireles utilizou em "Desvio Para o Vermelho"; ou mesmo colecionadores fictícios, como o Duda Miranda, de Marilá Dardot (MIRANDA, 2007), dentre tantos outros.

Apesar do recorte acima apresentado, dentre os colecionadores pesquisados, os modos de colecionar, estratégias e motivações são diversos. Alguns são compradores compulsivos de arte, dizem adquirir obras obsessivamente. $\mathrm{E}$ isso pode chegar a ser patológico e demandam cuidados terapêuticos. Outros, veem na compra de arte uma forma de investir dinheiro, compram e revendem a curto/médio prazo. Alguns investidores, inclusive, têm ações no Brasil Golden Art (BGA), fundo de investimentos e participações (FIP) atrelado à Bolsa de Valores de São Paulo (Bovespa). Existem também pessoas que veem no colecionismo uma espécie de atividade redentora frente a grandes infortúnios da vida, às experiências avassaladoras como a morte de um ente querido. Tem gente que, a partir de sua experiência de colecionismo, dedica-se integralmente à arte trabalhando na organização de feiras, abrindo galerias ou institutos. Outros, a partir de seus trabalhos com arte, começam a colecionar ("não posso vender aquilo que eu não compraria"7, me disse um vendedor). Tem também quem compre obras de arte para "construir-se socialmente como alguém". Algumas pessoas escolhem e compram arte "sozinhas", sem a consultoria direta de nenhum outro expert que não os galeristas. Outras, recorrem a serviços de curadores e advisers da arte. Certos colecionadores gostam de comprar obras direto dos artistas, em seus ateliês. Outros criticam tal prática "por desrespeitar o sistema da arte" e afirmam só comprar em galerias. Outros, ainda, como pudemos acompanhar recentemente na operação Lava Jato encabeçada pela polícia federal e pela figura do juiz Sérgio Moro, ou no famoso caso da coleção do Banco Santos, capitaneada por Edemar Cid Ferreira ${ }^{8}$, têm na arte uma forma de lavar dinheiro de caixa dois e de propina.

Uma pequena anedota me foi contata bem no início de minha pesquisa de campo. Nunca consegui confirmá-la, mas a tenho sempre em mente: em uma entrevista perguntaram ao diplomata Gilberto Chateaubriand, dono de umas das maiores coleções de arte brasileira moderna e contemporânea, o que era preciso para ser um colecionador. A resposta foi precisa: "Dinheiro". Outra anedota: estava um senhor artista em uma conversa com o filho e referiu-se a alguém como rico. Questionado sobre quão rica essa pessoa seria, respondeu: "Tão rico que coleciona obras de arte". Nesse caso o colecionismo não é apenas índice de riqueza, mas de uma riqueza mesmo dentre os parâmetros de riqueza. E essa, me parece é uma das principais imagens que temos dos colecionadores: pessoas muito ricas. E ela efetivamente corresponde a boa parte deles.

Mas nem todos os colecionadores são milionários ou super-ricos. Existem aqueles que, funcionários públicos, classe média (muitas vezes alta), ao invés de comprar uma segunda casa, fazer uma poupança ou gastar seu dinheiro com

\footnotetext{
${ }^{7}$ As citações em itálico e entre aspas ao longo do texto referem-se a fontes orais.

${ }^{8}$ Parte da coleção da massa falida do Banco Santos foi leiloada no final do ano passado, arrecadando quase 12 milhões de reais, $50 \%$ a mais que o valor inicial das (GAZZONI, 2016), em plena crise política e econômica. A coleção de arte era bastante eclética, de torsos romanos à contemporâneos chineses, passando pela arte moderna e contemporânea brasileira (o banqueiro Edemar Cid Santos também colecionava outras coisas, como documentos históricos e móveis - GONÇALVES FILHO, 2016).
} 
(outros) "luxos"/marcadores de riqueza, preferem "ter uma vida modesta e comprar arte" e, assim, nas palavras de um deles, "colecionar amigos". Conheci um colecionador nesse perfil que, segundo ele, fez parte de suas aquisições obras de artistas que, sem dinheiro, o procuravam oferecendo seus trabalhos para conseguir pagar o aluguel, por exemplo. "Eu não troco o fogão há anos. Não guardo dinheiro, eu não quero comprar imóveis. Tudo o que ganho gasto em arte". Outro colecionador que, hoje, tem uma empresa de design e presta serviços para artistas dando suporte à produção de suas obras (soluções de materiais e estrutura, ou executando determinadas peças), desde os tempos em que trabalhava como montador em exposições troca seu trabalho pelos dos artistas que, por vezes, veem nessas trocas a única forma de pagar por seus serviços. $E$ tem os casais de professores universitários que compram obras com pagamento parcelado - e que hoje têm trabalhos que valorizaram tanto que não poderiam comprá-los novamente - ou que colecionam gravuras, que costumam ser as mais acessíveis dentro do mercado. E "mesmo comprando obras baratas", informou um amigo de um desses casais, "vivem quebrados por causa da arte". E completou: "Ainda bem que não sofro desse mal". Tem também a coleção daquele engenheiro que se define como "classe média média" que, nas décadas de 1970 e 1980, começou a comprar obras de arte "para ajudar os amigos artistas, sempre ferrados de grana". Tornou-se colecionador, mas parou de comprar arte nos anos 2000 porque a prática ficou financeiramente insustentável além de ter "deixado de ser besta", segundo ele mesmo, referindo-se ao deslumbramento que sentia outrora em ser o centro das atenções de galeristas e a artistas já que, afinal, era um comprador de arte ativo.

Até aqui, falei sobre como a figura do colecionador tem diferentes motivações para comprar arte e como, embora boa parte daqueles que conheci sejam pessoas ricas ou super-ricas, existem colecionadores de arte de classes médias médias e médias altas. Obviamente o mercado de arte não é um mercado de subsistência, identifica-se mais com o mercado do luxo e, portanto, exclui a enorme maioria dos brasileiros, mesmo dentre aqueles poucos que se interessam e consomem arte contemporânea de outras maneiras (acompanhando exposições, por exemplo) ${ }^{9}$.

Há uma certa lógica "nativa" de classificação dentre aqueles que compram obras de arte que diferencia compradores, colecionadores e investidores e que é replicada em muitas falas sobre colecionismo e coleções de arte. Tratam-se de tipos ideais (WEBER, 1982) ${ }^{10}$, definidos a partir das relações que as pessoas que compram arte estabelecem com tal aquisição - e com a própria arte. Diz respeito também ao jogo de aproximação e distanciamento entre os domínios da arte e do dinheiro. Dentro dessa lógica, o comprador de arte é aquela pessoa que compra arte sem ser necessariamente uma colecionadora. Tem por objetivo decorar sua casa (ou a de terceiros, no caso dos decoradores e arquitetos), para presentear alguém, dentre outros motivos. De um modo geral, esse comprador não é visto por

\footnotetext{
${ }^{9}$ Estou pensando aqui o consumo não necessariamente no senso comum, atrelado ao pagamento de forma direta do consumidor por uma mercadoria, mas como prática também fruitiva, na esteira das reflexões da antropóloga Mary Douglas e do economista Baron Isherwood e seu livro "O mundo dos bens" (2004).

${ }_{10}$ A ideia do tipo ideal weberiano é funcionar como uma ferramenta analítica/de interpretação do mundo cujas categorias, enquanto ideais, não existem necessariamente de "forma pura" e, na prática, confundem-se entre si. Nesse sentido, por exemplo, os colecionadores podem ser também investidores, conjugando paixão e o potencial de valorização financeira de uma aquisição sua (como, me parece, o fazem de um modo geral). 
colecionadores, galeristas e outros experts em arte como uma pessoa com um profundo conhecimento na área - mas, quanto mais ele demonstra ter esse conhecimento, mais se aproxima da figura do colecionador. Ele pode ser tanto um comprador esporádico (que vai comprar uma ou poucas obras), como um possível futuro colecionador. É, de acordo com alguns galeristas, o principal cliente de grande parte das galerias em termos de porcentagem de vendas. Segundo um amigo galerista, "as galerias de pequeno/médio porte costumam ter apenas uns dois ou três colecionadores como clientes assíduos".

O colecionador é, como versamos acima, aquela pessoa que tem uma coleção e continua a constituindo, em um infindo work in process. Ter uma coleção tende a ser um eterno adquirir de obras. Uma crítica que ouvi ${ }^{11}$ e que revela outro aspecto importante do colecionismo foi de que determinada pessoa não era colecionadora porque tinha "um álbum de figurinhas, não uma coleção". "Como assim?", perguntei. "Álbum de figurinhas, oras, ela tem um trabalho de cada artista e pronto, não compra mais do que isso". Recorrentemente, nas falas sobre suas coleções, os colecionadores enfatizam a compra de mais de uma obra de um mesmo artista, como é o caso do banqueiro e colecionador José Olympio Pereira "[...] desses contemporâneos acho difícil ter um que a gente tenha menos de 10 obras. E se não temos vamos ter, porque seguimos, compramos, etc." (palestra na SP-Arte, $13 / 05 / 2011)^{12}$. Um colecionador, idealmente, segue os artistas que Ihe agradam.

Isso significa que ele acompanha o que o artista tem produzido, adquire seus trabaIhos a fim de incentivar a carreira desse artista e reafirmar suas escolhas/apostas como colecionador, valorizando, assim, a própria coleção.

O colecionador é, dentre os compradores de arte (comprador e investidor), aquele que potencialmente tem um maior entendimento daquilo que adquire. Mas, reafirmo, assim como o comprador, ou mesmo o investidor, os colecionadores não são simétricos dentro dessa categoria, eles não têm todos os mesmos conhecimentos em arte nem os mesmos interesses. Parte significativa dos colecionadores afirma ter começado a adquirir obras sem a pretensão de formar uma coleção ou de se tornar colecionador. Começaram "comprando uma ou outra peça" para decorar suas casas, ganhando um ou outro trabalho de presente de alguém, comprando certas obras porque apaixonaram-se por elas ou porque alguém sugeriu que tais trabalhos eram boas oportunidades de negócio. A partir do que muitas vezes é um primeiro contato com as artes visuais através da aquisição/posse de obras, essas pessoas narram outras aquisições e o início da construção de suas relações com as artes visuais mediadas pelo prazer de comprar arte e conviver com ela. Fala-se, então, de uma progressiva intensificação desse envolvimento a partir da ida a exposições; leitura de livros de artistas e sobre arte; do estudo da história da arte; da participação de conselhos de museus; de viagens para ver arte em bienais e feiras; das relações tecidas com artistas, galeristas, curadores, outros colecionadores. Não foram poucas as vezes que ouvi falar da intensificação desse envolvimento com arte como um caminho sem volta, uma espécie de patologia decorrente de uma metafórica picada de inseto. Frases como "quando vi, quando dei por mim, eu tinha uma coleção" foram recorrentes ao longo da pesquisa que embasa este artigo. Um

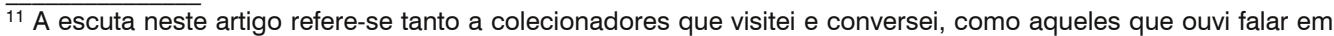
eventos (como as feiras de arte) ou ainda tive a oportunidade de ler a respeito.

${ }^{12}$ No presente artigo, só estão identificados colecionadores cujas falas foram proferidas publicamente e foram obtidas através de uma pesquisa na internet.
} 
galerista me afirmou: "a gente costuma dizer que um comprador de arte passa a ser colecionador quando continua comprando após decorar a casa, quando ele não tem mais espaço na parede, quando não tem mais onde colocar arte". Esse é, segundo o já citado José Olympio Pereira, o turning point da passagem do comprador de arte para o colecionador.

Salvo uma ou outra exceção, as narrativas de perceber-se enquanto colecionador, em geral, passava também por uma tomada de consciência de que se tinha um conjunto de obras numericamente significativo e que, enquanto conjunto, elas faziam "algum sentido". Ou seja, uma coleção de arte contemporânea é mais do que a soma de obras de arte, é um agrupamento de peças que dialogam entre si; que, juntas, "dizem algo", tratam de um determinado assunto, que pode ser o mais diverso (como artistas de uma geração, de uma certa localidade; um tema ou procedimento artístico específico); que formam discursos coerentes. Nesse sentido elas são, assim como as obras que as compõe, formas de enunciação. O colecionador expressa-se através de sua coleção. E talvez por isso certos colecionadores, referindo-se às pessoas que contratam advisers ou curadores para orientar suas compras, não compreendem como um terceiro sujeito possa fazer as escolhas de uma coleção particular. Nesse caso, há um forte vínculo entre coleção e colecionador. "É o meu gosto, sou eu que vou conviver com aquelas obras. Como eu vou delegar a aquisição das obras a um curador se sou eu que vou passar meus dias com elas? E se a pessoa escolhe algo que não me agrada, como é que eu fico?"

Mencionei acima a fala de um galerista afirmando que sabe-se que um cliente comprador de arte virou um colecionador "quando terminou de decorar sua casa [...] quando não tem mais onde colocar arte". Mas onde os colecionadores guardam suas obras? Tem quem não tenha, literalmente, um metro quadrado vago nas paredes de sua casa e guarde parte da coleção no guarda-roupa - às vezes em cima dele -, em armários na área de serviço, ou mesmo debaixo da cama. Outras pessoas criam acervos climatizados dentro de suas casas para guardar as coleções ou, ainda, verdadeiras galerias em seus jardins, como é o caso do casal Fernanda Feitosa e Heitor Martins, que são, respectivamente, criadora e diretora da SP-Arte e ex-presidente da Fundação Bienal (LONGMAN, 2015). Assim como José Olympio, tem quem compre outro(s) imóvel(imóveis) para abrigar a coleção - para um colecionador não rico, envolvido com o colecionismo "de longa data", o dinheiro para tal aquisição pode vir da venda de alguma obra que comprou há alguns anos por valores relativamente módicos, mas que atingiu preços astronômicos nos últimos tempos. Tem quem deixe (e aqueles que tentam deixar em vão) sua coleção sob comodato em algum museu que, em contrapartida à manutenção da mesma, pode(ria) exibir e emprestar suas peças a outras instituições. O contrato de comodato pode prever, ainda, a doação da coleção para o museu após a morte do colecionador. Essa é outra forma de abrir a coleção que tem o benefício de trazer ao público obras e conjuntos de obras tidos pelos atores das artes visuais como significativos e que estão nas mãos de colecionadores particulares, cuja importância justifica o investimento do estado em sua manutenção. Mas a prática do comodato, por outro lado, poderia levar colecionadores atrás de prestígio e tidos como oportunistas à montar coleções e delegarem sua manutenção ao estado. Há, ainda, colecionadores que constroem institutos para abrigar e abrir a coleção para o grande público - muitas vezes com os auxílios fiscais e de incentivo à cultura que podem 
pleitear através dos mesmos. A abertura da coleção, em geral, aparece nos discursos dos colecionadores com um tom filantrópico, como uma espécie de benfeitoria à comunidade, um préstimo à sociedade, mas ela também confere prestígio à própria coleção e ao colecionador - tão dedicado à arte e com uma coleção tão significativa, que abriu um instituto, "seu próprio museu". Contrariando umas das lógicas mais comuns da compra de coisas em geral, recorrentemente fala-se que uma obra escondida na casa ou no acervo de alguém não cumpre seu papel de arte; que "o colecionador é um guardião da obra de arte, mas ela é, por definição, um bem público" e, portanto, cabe a ele mantê-la disponível ao grande público. O colecionador deveria, então, zelar pela obra e emprestá-la às instituições que a solicitarem (desde que tenham condições de mantê-la bem conservada e em segurança). Conforme colocado, uma coleção é idealizada como um eterno work in process. Mas ela pode acabar. Por vezes esse fim pode ser bastante trágico, como é o caso dos incêndios, nada incomuns. Um exemplo disso foi um dos primeiros episódios que vivi em campo, na ocasião de uma conversa sobre o mercado de arte organizada pela ArtRio, em meados de 2012. Logo no início da apresentação de sua palestra, Jones Bergamin (presidente da Bolsa de Artes, casa de leilóes atuante no Rio de Janeiro e em São Paulo) foi avisado que o apartamento do marchand Jean Bogichi estava em chamas. O palestrante passou a informação para o público e a emoção tomou conta do ambiente. Logo depois, Bergamin, muito comovido, cancelou sua fala. O apartamento de Bogichi abrigava parte significativa de sua coleção e temia-se que ele não aguentasse tamanho golpe, pois, dizia-se naquele momento, sua paixão e dedicação às artes eram enormes e "aquela coleção era a vida dele". Mais tarde soube via imprensa que a coleção de Bogichi não foi integralmente comprometida, muito embora, dentre as obras destruídas estivesse 0 samba, tela "pintada em 1925 por Di Cavalcanti", principal item da coleção, que "derretera junto com a proteção de acrílico que a amparava" (KAZ, 11/2015). Mas, frente à comoção gerada pela situação dentre as pessoas presentes na palestra de Bergamin, pude entender que havia muito mais em jogo que dinheiro - por vezes muito dinheiro - em uma coleção. Coincidentemente ou não, um ano após ver parte de sua coleção em chamas, Jean Bogichi começou a enfrentar problemas pulmonares e, passados "dois anos de internações constantes - e cada vez mais longas -, o marchand romeno morreu de embolia pulmonar em junho de 2015, aos 87 anos" (id. ibid.).

Não são apenas acidentes que levam ao desmanche de coleções. Para "garantir a aposentadoria", ou por cansaço de cuidar da manutenção da coleção, ou por algum tipo de "desilusão com a coisa toda", um colecionador pode desfazerse de uma coleção que construiu durante décadas. Algumas vezes, casais colecionadores se separam e a coleção é desmembrada, distribuída entre o ex-casal e seus filhos, podendo também ser em partes ou integralmente pulverizada em leiIões. Não raramente o colecionador morre e seus herdeiros não têm interesse em cuidar da coleção e a vendem - em geral desmembrada, obra a obra, também em leilões. Mas há também os destinos tidos como felizes para uma coleção. Talvez o mais desejado dentre os mesmos por parte significativa dos colecionadores seja sua doação para algum museu, que as manteria relativamente intactas e com seu nome original. É claro que essas doações passam pelo crivo das próprias instituições (suas diretorias e conselhos). Não se aceita qualquer coleção em qualquer 
situação - o mesmo vale para uma obra específica. Ou a venda integral da coleção, ou de parte significativa dela, para algum museu (como o caso emblemático da venda da coleção de Adolpho Leirner para o Museum of Fine Arts de Houston, em 2007 - uma aquisição feliz para o museu e lamentada por grande parte dos atores brasileiros das artes visuais, que perderam para os Estados Unidos a coleção de arte construtiva brasileira mais importante que havia no Brasil).

Manter uma coleção sob os cuidados de um museu demanda da instituição investimento financeiro para a manutenção do acervo (que precisa ser climatizado, por exemplo), para a segurança, contratação de experts, dentre outros. Muitos atores da arte contemporânea questionam doações de coleções privadas porque pensam os museus como instituições de interesse público responsáveis pelos processos de valoração e legitimação de obras e artistas (e colecionadores!), pela "construção da memória" e idealmente por representar/apresentar (me faltaram palavras melhores) determinadas questões e visões de mundo coletivas. Para essas pessoas, um museu público receber de um colecionador privado uma coleção seria, também, receber um modo de olhar particular sobre as artes, um recorte das artes específico daquela pessoa que fez a doação. Politicamente, isso significa avalizar institucionalmente e publicamente tal recorte e, consequentemente, aquele que o fez.

Um exemplo de debate que levantou a questão acima colocada, versando também sobre o que seria uma coleção pública, gira em torno da apreensão de obras na operação Lava Jato e seu direcionamento para o Museu Oscar Niemeyer (MON), de Curitiba/PR, nos anos de 2015 e 2016. Segundo a polícia federal, as obras de arte aprendidas foram recebidas como propina pelos investigados da operação e encaminhadas, em diferentes lotes, para o MON. Na ocasião do recebimento de um desses lotes, li em minha timeline no facebook a seguinte postagem: "Museu do acaso. Novas coleções públicas formadas com a curadoria aleatória da Polícia Federal". Em um dos comentários do post, Paulo Reis, curador, crítico e professor de artes residente em Curitiba posicionou-se: "Eu diria pior, é [uma coleção formada] pelo olhar do bandido... Já aprendemos com Hans Haacke que a malha discursiva da compra e venda de uma obra de arte (Courbert, Seurat...) faz parte de sua história de visibilidade" (12/08/2015). Em janeiro de 2016, momento em que nova obras apreendidas na Lava Jato eram exibidas na segunda edição de uma mostra intitulada "Obras sobre a guarda do MON" (a outra edição esteve em cartaz de abril a novembro de 2015), Reis escreveu um novo post, que resume bem não apenas o posicionamento de vários atores das artes visuais sobre o caso, mas também conceitua o que seria, segundo muitos deles, uma coleção para um museu público:

[...] O texto de apresentação da diretora-presidente [do MON], presente no site do museu, afirma que "o museu cumpre a sua missão no sentido de preservar e abrigar coleções de arte e também de democratizar seu acesso aos visitantes". Dois grandes problemas de entendimento colocam-se aí. Primeiramente não há uma compreensão do que seja uma coleção, ao menos na acepção que interessaria a um museu de arte. Uma coleção é um agrupamento de obras estabelecido por razões históricas, artísticas e culturais e o que se exibe ali é um 
ajuntamento de obras usadas em operações financeiras, anuladas em seu valor cultural e transformadas unicamente em 'commodities', e isto, em minha opinião, jamais poderia ser denominado de coleção. $\mathrm{O}$ segundo ponto é o de que democratizar o acesso à arte não significa unicamente a presença física das obras numa sala de exposição, mas o acesso intelectual e crítico às obras de arte e a seus sistemas de significação e representação (essa sim, uma das maiores missões de um museu) [...]. (Paulo Reis, postagem no facebook realizada em 16/01/2016).

Falta versar aqui sobre o terceiro tipo ideal da sociologia nativa dos compradores de arte: $\mathbf{o}$ investidor. Investidora é aquela pessoa que adquire obras de arte para revendê-las. Seu objetivo, ao contrário do colecionador, não está "na arte em si, mas no dinheiro". Esse comprador, dizem, não se interessa pela qualidade artística do que compra, mas pelo seu potencial de lucro, não compra arte por paixão, mas pelo dinheiro. Fala-se de obras retiradas do mercado primário e lançadas cerca de três meses depois no mercado secundário ${ }^{13}$. Se o colecionador é a figura mais desejada pela galeria, o investidor é o oposto: o cliente que deve-se evitar, aquele em cujas mãos nenhum artista quer ver suas obras, a pessoa que, por colocar rapidamente os trabalhos no mercado secundário de arte, é acusada pelos demais atores do sistema, em especial pelos próprios artista, de entender mais de mercado do que de arte. O termo investidor foi acionado, em muitas das falas sobre colecionadores que acompanhei ao longo dos últimos anos, como uma categoria acusatória. Nas palavras de José Olympio, "arte tem que ser comprada por paixão, [...] pelo prazer [...]. Você conviver com o negócio só pela perspectiva de investimento é uma droga" (José Olympio Pereira, 13/05/2011). Uma droga porque seria equivalente a, segundo o próprio Olympio, dirigente de um banco de investimentos, comprar uma ação, colocar a cautela na parede da sala "e todo dia ficar olhando aquele negócio" (id. ibid.), que vai te lembrar o tempo todo que você é um investidor. Nesse caso, o que olhamos, nos vê, nos mostra sua perspectiva de nós mesmos (DIDI-HUBERMAN, 2014).

Finalizo o presente trabalho com um parêntese sobre a posse de obras de arte e a onomástica das coleções. "Ontem eu vi um Demian Hirst", "Estou vendendo uma [Beatriz] Milhazes" ou "Ganhei um Cildinho [Cildo Meirelles]", são exemplos de falas passíveis de serem ouvidas no contexto da arte contemporânea. Essas pessoas não estão necessariamente dizendo que viram o Demian Hirst, estão vendendo a Beatriz Milhazes ou ganharam o Cildo Meirelles versão miniatura: elas se referem aos trabalhos desses artistas. E elas os fazem porque, de certa maneira, os trabaIhos fazem parte dos artistas: há uma contiguidade entre os artistas e suas obras, os artistas parecem se distribuir através das mesmas. Nesse sentido, a obra de arte tem uma aura (id. ibid.) e ela é humana. Misturam-se, assim, nas obras de arte, pessoas e coisas. E, ao contrário do que afirmava Marx, nesse caso, os humanos não se objetificam frente as coisas, mas podem tornar-se super-humanos produtores de superobjetos (dadas as demandas de reconhecimento da especificidade e extraordinariedade dos artistas e daquilo que produzem). Colecionadores

${ }_{13}$ Por mercado primário de obras de arte, compreende-se o mercado da primeira venda/compra de uma peça. Por mercado de arte secundário, o mercado de revenda de obras de arte (leilões, galerias de arte moderna que trabalham com artistas já falecidos). 
idealmente seriam outros super-humanos, capazes de reconhecer a extraordinariedade de artistas e obras de arte e com capital para adquirir obras de arte. Se eu estiver certa e obras de arte forem os artistas distribuídos em coisas, um colecionador não coleciona "apenas" trabalhos de arte, mas os próprios artistas (em minha mente ecoa a frase de um colecionador que me afirmou: "não coleciono arte, coleciono amigos"). As coleções, por sua vez e em geral, recebem o nome de seus proprietários, daqueles que selecionam e reúnem coisas/pessoas e que as colocam em relação. Se a mesma lógica onomástica que acionei em relação aos artistas for aplicável aqui, as coleções tornam-se, mais do que conjuntos de coisas, extensões dos colecionadores. E veremos que, assim como uma obra de arte, uma coleção é, para boa parte dos atores do mercado, uma construção e, nesse sentido, uma autoria, cuja ação do autor é selecionar e colocar lado a lado coisas/artistas/ideias, construindo relações entre artefatos produzidas por terceiros e, através dessas relações, produzindo suas formas de enunciação. A coleção parece ter algo de íntimo, de pessoal, de intransferível. Se uma obra de arte é uma criação, uma coleção também o é. Assim como as obras são pensamentos, as coleções também o são. Se "a pintura pensa" (DIDI-HUBERMAN, 2012), a coleção pensa também.

\section{Referências}

BERTOLOSSI, Leonardo. Arte enquadrada e gambiarra. Tese. São Paulo: USP, 2014.

BULHÕES, Maria Amélia. "O sistema da arte mais além da sua simples prática". In: BULHÕES, Maria Amélia... [et. al]. As novas regras do jogo. Porto Alegre: Zouk, 2014, p. 15-43.

BURIGO, Juliana; CORDOVA, Dayana Zdebsky de. Conversas sobre arte. Curitiba: Máquina de Escrever, 2015.

CORDOVA, Dayana Zdebsky de. Artes visuais contemporâneas e seus fluxos. Dissertação de mestrado PPGAS/UFPR. Curitiba: 2010. Disponível em <https://goo.gl/A1UoXZ> Acesso: 20 janeiro 2016.

Flânerie. Monografia. Curitiba: DEAN/UFPR, 2005.

. [Sem Título]. Relatório de qualificação. São Carlos: PPGAS/UFSCar, 2016.

DIDI-HUBERMAN, Georges. A pintura encarnada. São Paulo: Editora Escuta, Editora Fapesp, 2012.

O que vemos, o que nos olha. São Paulo: Editora 34, 2014.

DOUGLAS, Mary; ISHERWOOD, Baron. O mundo dos bens. Rio de Janeiro: Editora UFRJ, 2009.

FETTER, Bruna W.. "A emergência de novas latitudes no mundo das artes" In: Visualidades, mar. 2015. Disponível em: <https://goo.gl/fG9TFD> Acesso: 19 outubro 2015. 
"Um bom negócio". In: BULHÕES, Maria Amélia... [et. al]. As novas regras do jogo. Porto Alegre: Zouk, 2014, p. 105-134.

FIALHO, Ana Letícia. “O Brasil está no mapa?”. In: A arte e suas instituições [site], 27 maio 2011.

Disponível em <https://goo.gl/iJoc63> Acesso: 20 junho 2017.

GEERTZ, Clifford. "A arte como sistema cultural". In: O saber local. Rio de Janeiro: Vozes, 1997, p. 142181.

GONÇALVES FILHO, Antonio. "Leilão de coleção de arte a massa falida do Banco Santos tem raridades". In: O Estado de São Paulo, 13 novembro 2016. Disponível em <goo.gl/TqBM2A> Acesso 20 junho 2017.

KAZ, Roberto. "O samba vive”. In: Revista Piauí, novembro 2015. Disponível em <https://goo.gl/1i8pRX.> Acesso: 08 outubro 2016.

LONGMAN, Gabriela. "A vida cercada de arte de Fernanda Feitosa”. In: Casa Vogue, 02 março 2015. Disponível em <https://goo.gl/u84ctn> Acesso: 20 junho 2017.

MIRANDA, Duda. A coleção Duda Miranda. Belo Horizonte: Rona Editora, 2007.

ROSA, Nei Vargas. "O Estado e o empreendedorismo do sistema da arte". In: BULHÕES, Maria Amélia... [et. al]. As novas regras do jogo. Porto Alegre: Zouk, 2014, p. 45-76.

STOCCO, Daniela. O mercado primário de arte contemporânea no Rio de Janeiro e em São Paulo. Tese. São Paulo: UFRJ/IFCS.

WEBER, Marx. Ensaios de Sociologia. Rio de Janeiro: LTC, 1982.

Recebido em 15/06/2017 - Aprovado em 04/08/2017 